\title{
A High-Efficiency Conformal Transmitarray Antenna Employing Dual-Layer Ultra-Thin Huygens Element
}

\author{
Li-Zhao Song, Student Member, IEEE, Pei-Yuan Qin, Senior Member, IEEE, and Y. Jay Guo, Fellow, IEEE
}

\begin{abstract}
A high-efficiency conformal transmitarray with ultra-thin dual-layer Huygens element is developed. The element consists of ' $I$ ' shape patches for magnetic response and ' $T$ ' shape stubs for electric response printed on two metal layers of a single substrate with only $0.5 \mathrm{~mm}$ thickness $\left(\lambda_{0} / 60\right.$ at 10 GHz). By tuning the magnetic and electric responses, the transmitting phase of the element can be changed. Eight elements are designed to cover quantized $360^{\circ}$ phase range with a maximal $1.67 \mathrm{~dB}$ loss. Then, the proposed elements are employed in a small conformal transmitarray design. To improve the antenna efficiency, the elements' dimensions are calculated by considering the oblique incidence effects. Finally, a cylindrically conformal transmitarray with a larger aperture size is simulated, fabricated and measured. It can achieve a measured gain of $20.6 \mathrm{dBi}$ with a $47 \%$ aperture efficiency.
\end{abstract}

Index Terms-Transmitarrays, Huygens metasurface, conformal antennas.

\section{INTRODUCTION}

Transmitarray antennas have been considered as competitive candidates to serve long distance communications for space and terrestrial wireless systems [1]. By leveraging the merits of lens antennas and microstrip phased arrays, they can achieve high gains without using complex and lossy feed networks and provide beam-steering capabilities by properly adjusting the aperture phase distribution [2-3].

The last two decades have witnessed substantial research efforts in enhancing the performance of transmitarrays e.g., improving the gain bandwidth [4-7], achieving multi-band operation [8-9], reducing the entire volume [10-14] and realizing beam steering functionality [15-18]. Regarding the abovementioned novel transmitarray prototypes, most of them employed multi-layer array elements, i.e., at least three metal layers printed on two dielectric substrates separated by air gaps or dielectric materials. Generally, the total thickness of the elements varies from $0.3 \lambda_{0}-1 \lambda_{0}$ ( $\lambda_{0}$ is the wavelength in the free space). Significant research efforts have been devoted to reduce the thickness of the elements in order to reduce the

Manuscript received July 31, 2019; revised April 22, 2020; accepted July 19, 2020. This work was supported by the Australia Research Council Discovery Program under Grant DE170101203 (Corresponding author: Pei-Yuan Qin)

The authors are with the Global Big Data Technologies Centre (GBDTC), University of Technology Sydney (UTS), Ultimo, NSW 2007, Australia. (pyqin1983@hotmail.com) entire profile of transmitarrays and/or make them attractive to conformal designs.

In [6], a wideband transmitarray is developed using a three-layer element with a thickness of $0.22 \lambda_{0}$. The peak efficiency of the antenna is $40.7 \%$. As reported in [10], a three-layer metallic unit without air gap shows a low profile of $1 \mathrm{~mm}\left(0.033 \lambda_{0}\right)$ overall thickness and is employed for transmitarray design with a $36 \%$ aperture efficiency. In [12], a thin transmitarray with a more than $30 \%$ efficiency is developed using three-metal-layer antenna elements with a thickness of $1.6 \mathrm{~mm}\left(0.07 \lambda_{0}\right.$ at $\left.13.5 \mathrm{GHz}\right)$. Although the thickness of the above transmitarray elements has been considerably reduced, they are three-metal-layer structures. Precise alignment and attachment of multilayers would be very challenging and costly, especially at high frequencies. This is one of the main reasons that many dual-layer reflectarrays, i.e. one metal layer printed on a grounded substrate, are developed [19-21]. However, only a few reports on dual-layer transmitarray elements have been published. In [22], a 1.5 -mm-thick $\left(0.1 \lambda_{0}\right.$ at $\left.20 \mathrm{GHz}\right)$ transmitarray element is developed consisting of two modified Malta crosses printed on two sides of a dielectric substrate with four vertical-plated through vias. A $40 \%$ antenna efficiency is realized. In [13], a thin planar lens antenna with an efficiency of about $26 \%$ is presented using gradient metasurface elements. The element consists of two metal layers printed on a single substrate with a thickness of $3 \mathrm{~mm}\left(0.1 \lambda_{0}\right.$ at $\left.10 \mathrm{GHz}\right)$.

Another important motivation for using dual-layer ultrathin elements is for conformal antenna designs. Conformal transmitarrays [23-25], which are developed to follow the shapes of various mounting platforms, e.g., aircrafts and unmanned aerial vehicles (UAV), have attracted much attention due to their capabilities to meet aerodynamic requirements. Considering the current manufacturing technology, one of the most feasible methods to implement conformal transmitarrays is to employ ultra-thin array elements with a thickness of about $0.5 \mathrm{~mm}$ for the ease of bending to make the antenna conformal. It should be noted that direct ink printing technology can do metal printing on a curved structure. However, to realize multi-layer metal printing on curved surface is a very expensive and technically difficult task, which may make conformal transmitarrays unaffordable for many applications.

Regarding the aforementioned dual-layer array elements, as their thickness is around $0.1 \lambda_{0}$, they are only suitable for conformal transmitarrays operating at above $30 \mathrm{GHz}\left(\lambda_{0}=10\right.$ 
$\mathrm{mm}$ ) for the ease of bending. Also, elements with vias are not preferable for conformal designs. However, transmitarrays working below $30 \mathrm{GHz}$ are highly desired by many applications, e.g., 5G systems and satellite systems. Therefore, an ultra-thin element without any vias which can be employed for conformal transmitarrays operating below 30 $\mathrm{GHz}$ is desperately needed. It should be noted that although using high dielectric substrate may be able to reduce the thickness of the array element, antenna efficiency will be significantly affected due to the losses and the total cost of the array will be increased. Another straightforward method is to compress the total thickness of the multi-layer element. However, this will reduce the antenna efficiency significantly as the element loss is increased [25]. Actually, there is always a tradeoff between the thickness of the array and its efficiency. It can be found that the efficiency of the transmitarray is less than $40 \%$ when the thickness of the element is about $0.1 \lambda_{0}$. Therefore, a key challenge for conformal designs is to develop ultra-thin array elements with a high transmitting efficiency.

In this paper, Huygens metasurface theory is employed to develop an ultra-thin dual-layer element for high-efficiency conformal transmitarrays. Huygens elements [26] can be used for transmitarrays as they are capable of realizing nonreflection and total transmission with sub-wavelength thickness, making it be a good candidate to provide a high efficiency and a low profile in transmitarray design. However, most of the currently reported Huygens elements are multilayer structures. In [27], the element consists of three metal layers using two vias to connect the first and the third layer to create a current loop for magnetic response. The second layer is for electric response. The total thickness is $3 \mathrm{~mm}$ at $10 \mathrm{GHz}$ $\left(0.1 \lambda_{0}\right.$ at $\left.10 \mathrm{GHz}\right)$. The elements in [28] consist of three-layer patterned metallic surfaces to mimic one electric dipole and one magnetic dipole printed on two bonded substrates. The thickness of the element is $0.4 \mathrm{~mm}\left(0.1 \lambda_{0}\right.$ at $\left.77 \mathrm{GHz}\right)$. In addition, there are some two-layer Huygens elements [29-30] that can introduce the electric and magnetic currents on two metal layers separately. However, the main limitation is that discrete printed circuit board tiles have to be made for each array element and the boards are stacked into an array. Compared with fully planar structures [27-28], this makes it more difficult to assemble a large surface.

From the above discussions, one can conclude that innovation is needed to develop dual-layer ultra-thin Huygens elements for high-efficiency transmitarray antennas, especially the conformal ones. In this paper, we developed a two-layer Huygens element without any metallic vias first. The element's thickness $h$ is $0.5 \mathrm{~mm}\left(\lambda_{0} / 60\right.$ at $\left.10 \mathrm{GHz}\right)$. It consists of a pair of symmetrical 'I' shape patches on top and bottom layers and double ' $T$ ' shape strips located on the margin of two layers to mimic a magnetic dipole and electric dipole, respectively. Second, for transmitarray applications, we design eight elements with different dimensions to cover a quantized $360^{\circ}$ phase range, and the highest element loss is $1.67 \mathrm{~dB}$. Third, a cylindrically conformal transmitarray is developed employing the developed Huygens elements. The measured aperture efficiency is found to be $47 \%$, which is much higher than the conformal transmitarray previously developed by the authors' group [25] and other planar transmitarrays with similar thickness. The element in [25] is a triple-layer frequency-selective surface (FSS) structure and the insertion loss is up to $3.6 \mathrm{~dB}$ when its thickness is about $\lambda_{0} / 25$ at $25 \mathrm{GHz}$. To the authors' best knowledge, the developed conformal transmitarray is the first one with a high antenna efficiency and the thinnest aperture.

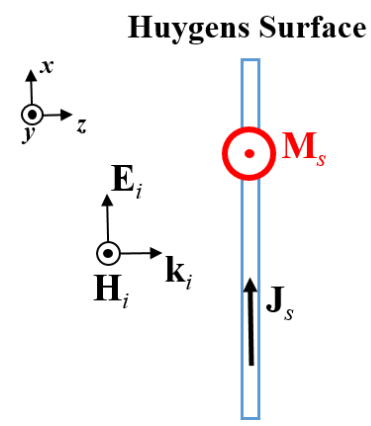

(a)
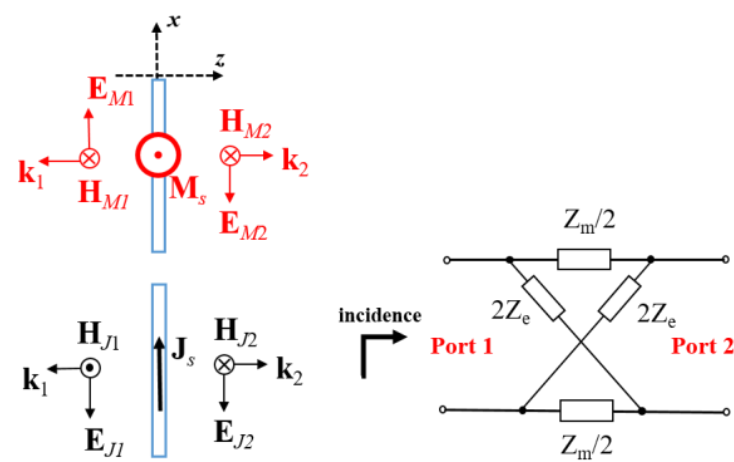

(b)

(c)

Fig. 1 Huygens surface: (a) Field sketch with macro-perspective; (b) Fields generated by E-current and M-current separately; (c) Equivalent circuit model.

The rest of this paper is organized as follows. In Section II, a detailed element design procedure is developed based on Huygens surface theory. A cylindrically conformal transmitarray based on the proposed element is simulated and analyzed in Section III. As a verification, a prototype is fabricated and measured in Section IV. The paper concludes in Section V.

\section{HUYGENS ELEMENT DESIGN}

\section{A. Huygens Surface Theory}

As shown in Fig. 1(a), when the incidence wave impinges on a Huygens surface, both the surface electric current Js and the magnetic current Ms would be induced, resulting in reflection and transmission waves which depend on the electric and magnetic current densities. Once E-current and M-current are excited, each of them can be taken as a source to generate electromagnetic fields on both sides of the surface. The Huygens surface can be analyzed from electric and 
magnetic sources separately, and the generated waves from two sources in $z<0$ and $z>0$ regions are shown in Fig. 1(b).

For a single E-current surface, it would satisfy the boundary conditions:

$\boldsymbol{z} \times\left[\boldsymbol{E}_{e}\left(z=0_{+}\right)-\boldsymbol{E}_{e}\left(z=0_{-}\right)\right]=0$

$\mathbf{z} \times\left[\boldsymbol{H}_{e}\left(z=0_{+}\right)-\boldsymbol{H}_{e}\left(z=0_{-}\right)\right]=\boldsymbol{J}_{\boldsymbol{s}}=\frac{1}{z_{e}} \cdot \boldsymbol{E}_{t e}(z=0)$

where $\boldsymbol{E}_{\mathrm{e}}$ and $\boldsymbol{H}_{\mathrm{e}}$ denote the electric and magnetic field intensities generated from E-current, respectively. $\boldsymbol{E}_{\text {te }}$ is the tangential part of $\boldsymbol{E}_{\mathrm{e}}$, and $\mathrm{Z}_{\mathrm{e}}$ represents surface electric impedance. By inserting the fields generated from $\boldsymbol{J}_{\boldsymbol{s}}$, as denoted in Fig. 1(b), into equation (1) and (2), we can get

$\boldsymbol{E}_{J 1}=\boldsymbol{E}_{J 2}$

$\boldsymbol{Z} \times\left(\boldsymbol{H}_{J 2}-\boldsymbol{H}_{J 1}\right)=\boldsymbol{J}_{\boldsymbol{s}}=\frac{\boldsymbol{E}_{\boldsymbol{t} \boldsymbol{e}}(z=0)}{Z_{e}}$

The tangential electric field on the surface is:

$\boldsymbol{E}_{t e}(z=0)=\boldsymbol{E}_{J 1}+\boldsymbol{E}_{i}$, or $\boldsymbol{E}_{J 2}+\boldsymbol{E}_{i}$

where $\boldsymbol{E}_{J 1}$ and $\boldsymbol{H}_{J 1}$ are the fields generated by $\boldsymbol{J}_{s}$ in $\mathrm{z}<0$ region, while $\boldsymbol{E}_{J 2}$ and $\boldsymbol{H}_{J 2}$ are the ones in z $>0$ region, and $\boldsymbol{E}_{i}$ refers to the incident field which exists in the whole area. Then, we can derive

$\boldsymbol{E}_{J 1}+\boldsymbol{E}_{i}=Z_{e} \cdot \boldsymbol{J}_{\boldsymbol{s}}=Z_{e} \cdot \boldsymbol{z} \times\left(\boldsymbol{H}_{J 2}-\boldsymbol{H}_{J 1}\right)=\frac{-2 Z_{e}}{\eta} \cdot \boldsymbol{E}_{J 1}$

$\boldsymbol{E}_{\boldsymbol{J 1}}=\frac{-\eta}{2 Z_{e}+\eta} \boldsymbol{E}_{\boldsymbol{i}}$

where $\eta$ denotes the wave impedance in free space. For a single M-current surface, it would satisfy the following boundary conditions:

$$
\begin{gathered}
-\boldsymbol{z} \times\left[\boldsymbol{E}_{m}\left(z=0_{+}\right)-\boldsymbol{E}_{m}\left(z=0_{-}\right)\right]=\boldsymbol{M}_{\boldsymbol{s}} \\
=Z_{m} \cdot \boldsymbol{H}_{t m}(z=0)
\end{gathered}
$$

$\mathbf{z} \times\left[\boldsymbol{H}_{m}\left(z=0_{+}\right)-\boldsymbol{H}_{m}\left(z=0_{-}\right)\right]=0$

where $\boldsymbol{E}_{m}$ and $\boldsymbol{H}_{m}$ denote the electric and magnetic field intensities generated from M-current, respectively. $\boldsymbol{H}_{\mathrm{t} m}$ is the tangential part of $\boldsymbol{H}_{m}$, and $\mathrm{Z}_{m}$ represents surface magnetic impedance. With similar derivation process to the E-current surface, we can obtain

$\boldsymbol{E}_{M 1}=\frac{z_{m}}{z_{m}+2 \eta} \boldsymbol{E}_{i}$

Finally, for a complete Huygens surface with both E-current and M-current, as shown in Fig. 1(a), we denote reflection and transmission coefficients as $R$ and $T$, respectively, as given in $[29,31]$. Then one obtains

$R=\frac{\left(\boldsymbol{E}_{J 1}+\boldsymbol{E}_{M 1}\right) \cdot \widehat{\boldsymbol{x}}}{\boldsymbol{E}_{i} \cdot \widehat{\boldsymbol{x}}}=\frac{-\eta}{2 Z_{e}+\eta}+\frac{Z_{m}}{Z_{m}+2 \eta}$

$T=\frac{\left(E_{J 2}+E_{M 2}+E_{i}\right) \cdot \widehat{x}}{E_{i} \cdot \widehat{x}}=\frac{2 Z_{e}}{2 Z_{e}+\eta}-\frac{Z_{m}}{Z_{m}+2 \eta}$

After doing transformation of equation (11)-(12), we get

$Z_{e}=\frac{\eta}{2} * \frac{1+R+T}{1-R-T}$

$$
Z_{m}=2 \eta * \frac{1+R-T}{1-R+T}
$$

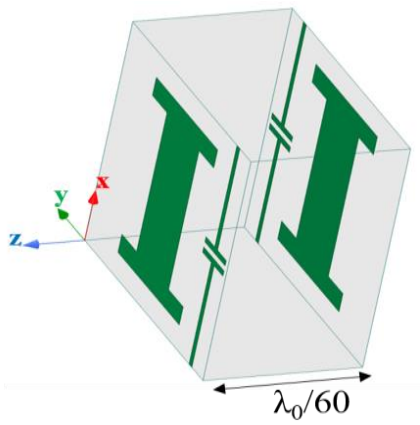

(a)
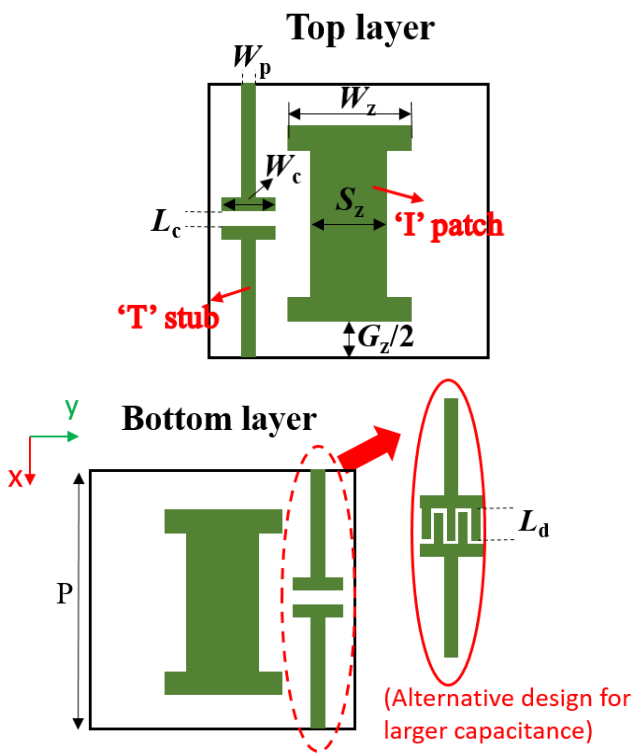

(b)

Fig. 2 Developed two-layer Huygens element model: (a) 3D structure; (b) top and bottom layers.

Therefore, the Huygens surface is capable to realize nonreflection and full-transmission with variable transmission phase $\varphi_{t}$, referred as $R=0, T=e^{j \varphi_{t}}$, as long as it satisfies

$Z_{e}=\frac{j \eta}{2 \tan \left(\varphi_{t} / 2\right)}$

$Z_{m}=-j 2 \eta \tan \left(\frac{\varphi_{t}}{2}\right)$

It can be seen from (15) and (16) that the electric and magnetic surface impedances are related to the transmitting phase. In another word, for each specific transmitting phase, there are corresponding surface impedances. In the next subsection, we will develop Huygens elements for specified transmitting phases. As indicated in [32-33], the whole Huygens surface can be equivalent to be a circuit model as shown in Fig. 1(c), and $Z_{\mathrm{e}}$ and $Z_{\mathrm{m}}$ can be defined by $\mathrm{Z}$ matrix from microwave network theory:

$Z_{e}=\frac{Z_{11}+Z_{21}}{2}$ 
$Z_{m}=2 *\left(Z_{11}-Z_{21}\right)$

\section{B. Element Synthesis}

The schematics of the developed Huygens element is given in Fig. 2. It consists of two metallization layers printed on two sides of a 0.5 -mm-thick substrate (Dielectric Constant $3.55, \tan \delta=0.0027)$. The substrate thickness is selected as 0.5 $\mathrm{mm}$ in this work in order to make it bendable. The ' $\mathrm{I}$ ' shape patches on the centre of top and bottom layers have exactly the same dimensions. Besides, one pair of two ' $T$ ' shape stubs are printed on each side of the substrate but at different positions. The distance between ' $\mathrm{T}$ ' stubs and the edge of the cell is $0.8 \mathrm{~mm}$. The period of the unit cell $\mathrm{P}$ is $8.5 \mathrm{~mm}$.

For many three-layer Huygens element, the metal traces on the first and third layers are used to generate a current loop to be equivalent to a magnetic dipole, while the trace in the middle layer is for introducing an electric dipole. For our developed element, only two metal layers are used and the substrate is significantly thinner. When a $x$-polarized wave impinges on the element, the ' $\mathrm{I}$ ' shape patches on top and bottom layers produce currents with opposite directions, thereby generating a current loop, which can be equivalent to a magnetic dipole. This will be verified in the current distribution shown in the next sub-section. Two pairs of ' $T$ ' shape stubs will produce currents along $x$-axis with the same direction, thereby introducing an electric dipole. These ' $\mathrm{T}$ ' shape stubs will not affect the magnetic response, while the 'I' shape patches have influence on the electric response. Therefore, the 'I' shape patches will be designed first. Then, the ' $\mathrm{T}$ ' shape stubs will be designed to control the electric response.

The magnetic response related to the magnetic surface impedance $Z_{\mathrm{m}}$ can be adjusted by changing the capacitive or inductive properties of the 'I' shape patches, which are related to the patch dimensions $W_{z}, G_{z}$ and $S_{z}$. The electric response related to the electric surface impedance $Z_{\mathrm{e}}$ can be manipulated by varying the values of $L_{c}, W_{c}$ and $W_{p}$. In some cases where large capacitance between the two ' $\mathrm{T}$ ' shape stubs is needed, e.g., the element is illuminated under large oblique incidence angles which would be discussed in Section III, the interdigital parasitic strips with length $L_{d}$ will be adopted for each pair, as shown in the inset of Fig. 2(b). For an $x$-polarized incident wave, the transmitting phase of the Huygens element can be varied by changing the element's dimensions. However, it cannot be continuously changed when varying only one or two dimensions of the elements. An optimization on the element's entire dimensions would be needed to achieve a continuous phase change, which may make the design of transmitarrays very complicated. Instead, quantized phase distribution is employed. In this work, eight elements are designed to achieve a 3-bit quantized phase distribution. The detailed phase points and corresponding $Z_{\mathrm{m}}$ and $Z_{\mathrm{e}}$ values calculated from (15) and (16) are listed in Table I.

As discussed in the last paragraph, the dimensions of the 'I' shape patches of the element will be determined first for the magnetic response. At this step, only the 'I' shape patches are modelled on the element and simulated without the two ' $\mathrm{T}$ ' shape stubs. Then the two ' $\mathrm{T}$ ' shape stubs are added to the element and the model is simulated for electric response.

TABLE I

HUYGENS PROPERTIES FROM THEORETICAL CALCULATION WITH QUANTIZED $360^{\circ}$ PHASE COVER

\begin{tabular}{|c|c|c|c|}
\hline Element No. & Phase & $\operatorname{Im}\left(Z_{e}\right) / \mathrm{k} \Omega$ & $\operatorname{Im}\left(Z_{m}\right) / \mathrm{k} \Omega$ \\
\hline 1 & $-15^{\circ}$ & -1.43 & 0.1 \\
\hline 2 & $-60^{\circ}$ & -0.33 & 0.44 \\
\hline 3 & $-105^{\circ}$ & -0.14 & 0.98 \\
\hline 4 & $-150^{\circ}$ & -0.05 & 2.81 \\
\hline 5 & $-195^{\circ}$ & 0.02 & -5.72 \\
\hline 6 & $-240^{\circ}$ & 0.11 & -1.31 \\
\hline 7 & $-285^{\circ}$ & 0.25 & -0.58 \\
\hline 8 & $-330^{\circ}$ & 0.7 & -0.2 \\
\hline
\end{tabular}

TABLE II

PROPERTIES OF HUYGENS ELEMENTS

\begin{tabular}{|c|c|c|c|c|c|c|c|}
\hline $\begin{array}{c}\text { Element } \\
\text { No. }\end{array}$ & $\begin{array}{c}\operatorname{Im}\left(Z_{e}\right) \\
/ \mathrm{k} \Omega\end{array}$ & $\begin{array}{c}\operatorname{Im}\left(Z_{m}\right) \\
/ \mathrm{k} \Omega\end{array}$ & $\begin{array}{c}\left|\mathrm{S}_{21}\right| \\
/ \mathrm{dB}\end{array}$ & $\angle S_{21}$ & $\begin{array}{c}\mathrm{Wz} \\
/ \mathrm{mm}\end{array}$ & $\begin{array}{c}\mathrm{Wc} \\
/ \mathrm{mm}\end{array}$ & $\begin{array}{c}\mathrm{Lc} \\
/ \mathrm{mm}\end{array}$ \\
\hline 1 & -2.3 & 0.13 & -0.16 & $-14^{\circ}$ & 3.6 & 1.3 & 0.1 \\
\hline 2 & -0.35 & 0.17 & -0.42 & $-41^{\circ}$ & 3.8 & 1.6 & 0.1 \\
\hline 3 & -0.12 & 0.64 & -1 & $-100^{\circ}$ & 4.1 & $/$ & $/$ \\
\hline 4 & -0.04 & 1.6 & -1.67 & $-153^{\circ}$ & 4.19 & 1.2 & 0.6 \\
\hline 5 & -0.02 & -0.44 & -1.66 & $-187^{\circ}$ & 4.2 & 1.2 & 0.37 \\
\hline 6 & 0.1 & -1.1 & -1.36 & $-241^{\circ}$ & 4.25 & 1.5 & 0.4 \\
\hline 7 & 0.22 & -0.52 & -0.86 & $-284^{\circ}$ & 4.3 & 1.62 & 0.4 \\
\hline 8 & 0.94 & -0.25 & -0.5 & $-330^{\circ}$ & 4.4 & 1.62 & 0.35 \\
\hline
\end{tabular}

Floquet ports with master-slave boundaries of 3D electromagnetic (EM) simulation software HFSS is used for the simulation. In this work, $W_{z}$ values would be tuned for magnetic response, while $S_{z}$ and $G_{z}$ are set as $2.3 \mathrm{~mm}$ and 1.7 $\mathrm{mm}$, respectively, for simulation simplicity. Moreover, $L_{c}$ and $W_{c}$ are varied for tuning electric response with $W_{p}=0.2 \mathrm{~mm}$. The dimensions, transmitting phases and magnitudes for the eight elements are given in Table II.

Fig. 3 shows the parametric studies on $W_{z}, L_{c}$ and $W_{c}$ based on element 1 . When one parameter is studied, the other two are kept unchanged as listed in Table II. As shown in Fig. 3 (a), $Z_{m}$ curve moves to lower band as $W_{z}$ increases, which provides a higher capacitance between 'I' shape patches of two adjacent elements. Besides, as seen in Fig. 3 (b) and (c), the $Z_{e}$ curve shifts left as $W_{c}$ increases, and it has the same changing trend when $L_{c}$ is decreased. This means $Z_{\mathrm{e}}$ would move to lower band when the capacitance between two ' $T$ ' shape stubs of each element increases. Furthermore, as seen in Fig. $4, L_{c}$ has almost no effect on the magnetic response at the desired frequency $10 \mathrm{GHz}$ for a changing range between $0.05 \mathrm{~mm}$ and $0.65 \mathrm{~mm} . W_{c}$ is found to have little influence on the magnetic response either, which is not shown here due to the space limit. This is the reason why magnetic and electric responses can be designed independently. 


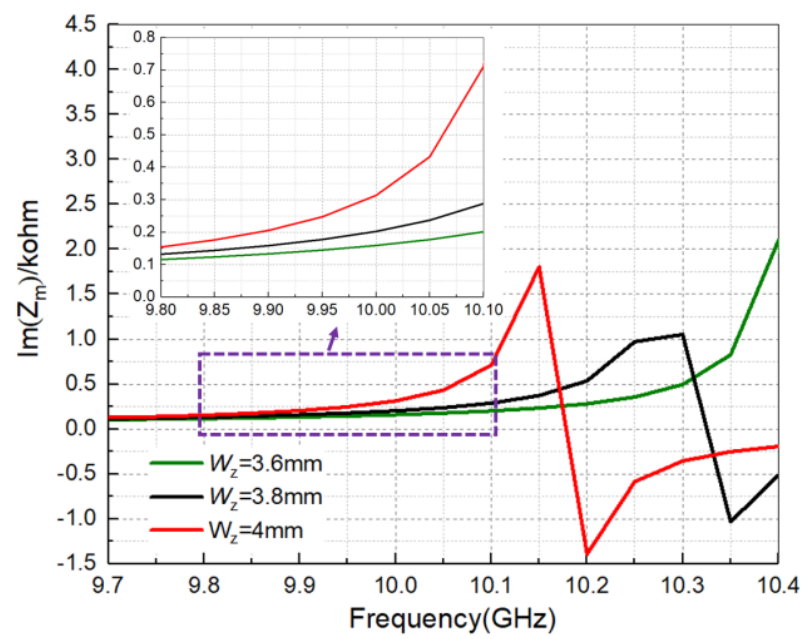

(a)

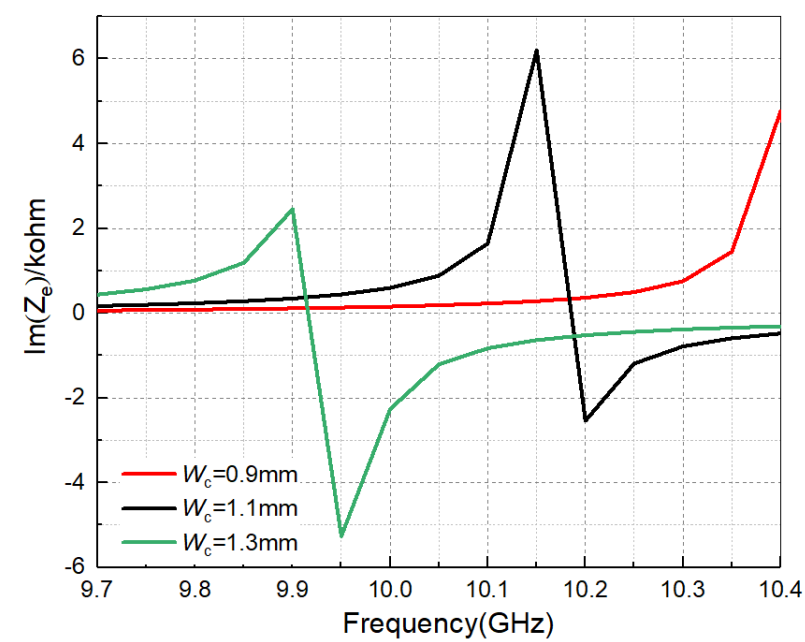

(b)

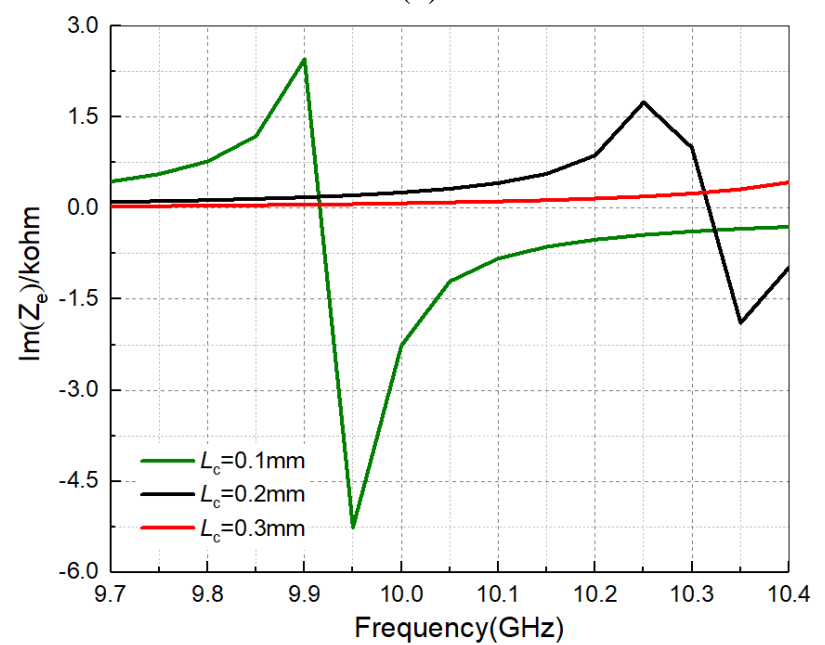

(c)

Fig. 3 Parametric studies for element 1: (a) Simulated $Z_{m}$ with different $W_{z}$; (b) Simulated $Z_{e}$ with different $W_{c}$; (c) Simulated $Z_{e}$ with different $L_{c}$

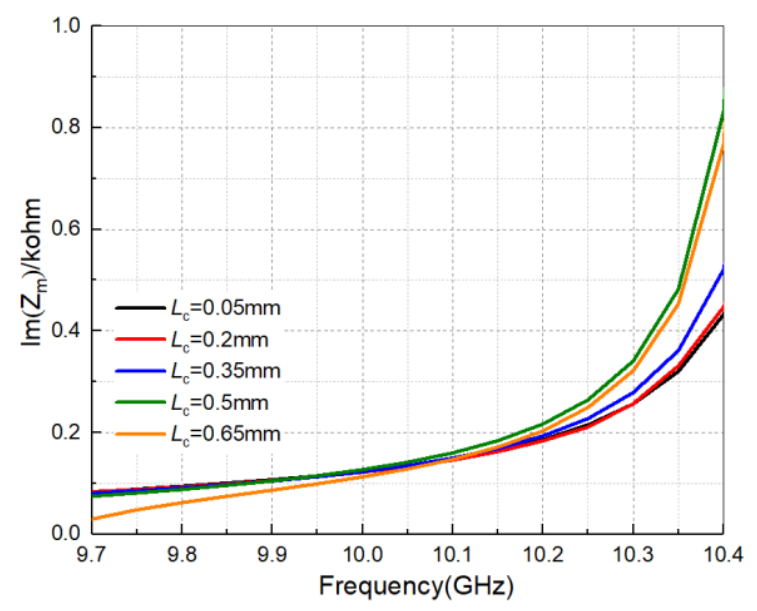

Fig. 4 Simulated $Z_{m}$ with different $L_{c}$.

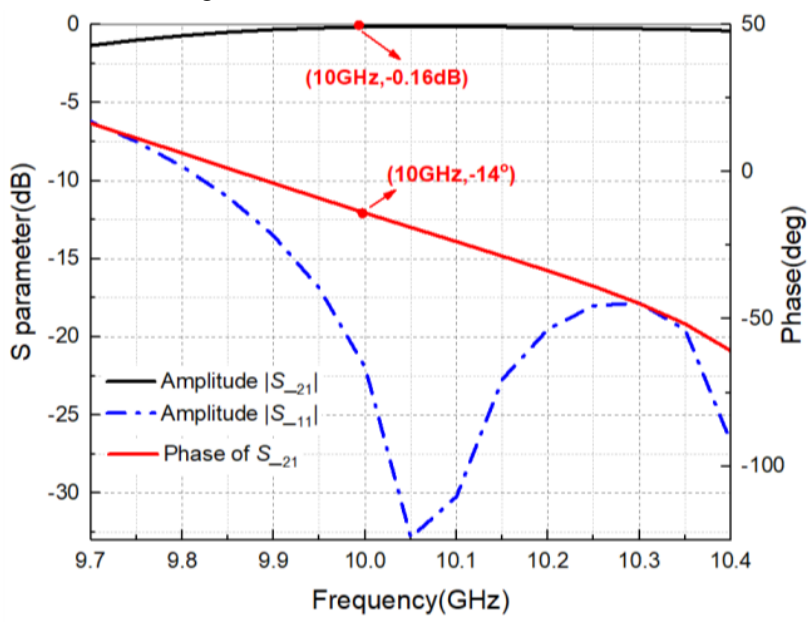

Fig. 5 Simulated $S_{-21}$ and $\left|S_{-11}\right|$ for element 1.

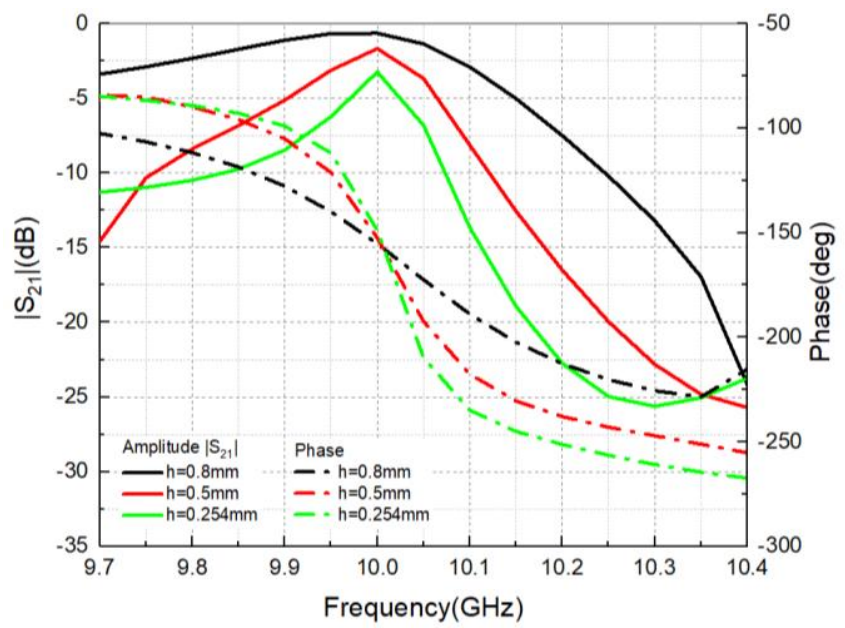

Fig. 6 Simulated S parameter of element 4 with different substrate thickness values.

By using the above parametric studies, an iterative method is employed to obtain other elements' dimensions at $10 \mathrm{GHz}$. First, the $\mathrm{Z}$ matrix of an initial element model is simulated under periodic boundary condition, and the values of $Z_{\mathrm{m}}$ and $Z_{\mathrm{e}}$ can be obtained based on (17)-(18). Then, the dimensions are further adjusted to make $Z_{\mathrm{m}}$ and $Z_{\mathrm{e}}$ close to the required 
values listed in Table I to achieve the desired transmitting phase. For element 3, the two ' $\mathrm{T}$ ' shape stubs are not needed as the "I" shape patch can provide sufficient electric response. It should be noted that ideal Huygens element should realize a full transmission without any loss. However, as the developed elements use two metal layers to mimic a Huygens element and the substrate is lossy, small transmission loss is expected. The losses are found to be comparable to those three-layer Huygens elements [28]. Moreover, for some specific phase values, the transmission loss of the element is larger than $2 \mathrm{~dB}$. In this case, small variations on the phase values are made to lower the loss. For example, for element 5 , the required phase is $-195^{\circ}$, while the synthesised phase is $187^{\circ}$. Here, a compromise between phase error loss and amplitude loss should be made. After finding the elements' dimensions for each phase value, the transmission coefficients for each element can be obtained. The $S_{21}$ result for element 1 is given in Fig. 5 as an example. It can be seen that the element loss is only $0.16 \mathrm{~dB}$ at $10 \mathrm{GHz}$ and its phase value is $-14^{\circ}$ which is close to the desired value $-15^{\circ}$ listed in Table I.

TABLE III

DIMENSIONS OF ELEMENT 4 WITH DIFFERENT SUBSTRATE THICKNESS

\begin{tabular}{|c|c|c|c|c|c|c|}
\hline $\begin{array}{c}\text { Thickness } \\
\mathrm{h} / \mathrm{mm}\end{array}$ & $\begin{array}{c}\mathrm{Wp} \\
/ \mathrm{mm}\end{array}$ & $\begin{array}{c}\mathrm{Wz} \\
/ \mathrm{mm}\end{array}$ & $\begin{array}{c}\mathrm{Wc} \\
/ \mathrm{mm}\end{array}$ & $\begin{array}{c}\mathrm{Lc} \\
/ \mathrm{mm}\end{array}$ & $\begin{array}{c}|\mathrm{S} 21| \\
/ \mathrm{dB}\end{array}$ & $\angle S_{21}$ \\
\hline 0.254 & 0.2 & 4.19 & 1.2 & 0.35 & -3.2 & $-149^{\circ}$ \\
\hline 0.5 & 0.2 & 4.19 & 1.2 & 0.6 & -1.67 & $-153^{\circ}$ \\
\hline 0.8 & 0.5 & 3.97 & 1.2 & 0.6 & -0.6 & $-153^{\circ}$ \\
\hline
\end{tabular}

We examine the effects of the substrate thickness on the transmission loss of the elements. We take the element 4 (with a transmitting phase of $-153^{\circ}$ from Table II) as an example. Under three different substrate thickness values, three different models of element 4 are designed. Their dimensions are given in Table III and the phase and magnitude of transmission coefficients are compared in Fig. 6. It can be seen that as the thickness reduces from $0.8 \mathrm{~mm}$ to $0.254 \mathrm{~mm}$, the transmission loss increases from $0.6 \mathrm{~dB}$ to $3.2 \mathrm{~dB}$. This is due to the fact that the balanced condition between electric and magnetic responses is broken when the thickness of the substrate is reduced too much. It is known that the magnetic current depends on the area of the current loop [34]. As demonstrated in Fig. 7 (b) and (d), the area of current loop is proportional to the thickness of substrate. If the thickness is too small, the magnetic current will become too weak, thereby being unable to balance the electric current. Therefore, in order to make a good balance and minimize the element loss, a thicker substrate should be employed. However, for the ease of bending, $0.5 \mathrm{~mm}$ is chosen to balance the thickness and loss. Moreover, we check the current distributions for element 1 at different times, as shown in Fig. 7. It can be seen that the currents on the two ' $I$ ' shape patches form loops as at $\mathrm{t}=\mathrm{T} / 4$ and $3 \mathrm{~T} / 4$ ( $\mathrm{T}$ is one time period), which provide the equivalent magnetic response. The phase interval between maximum electric and magnetic magnitude responses is $90^{\circ}$, which satisfy non-reflection Huygens element requirement [26, 34].

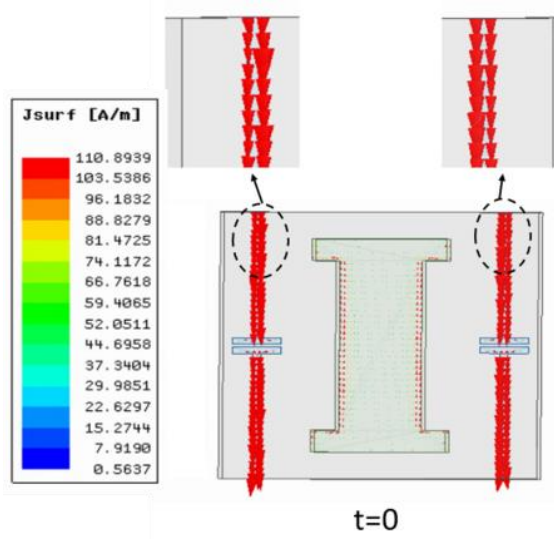

(a)

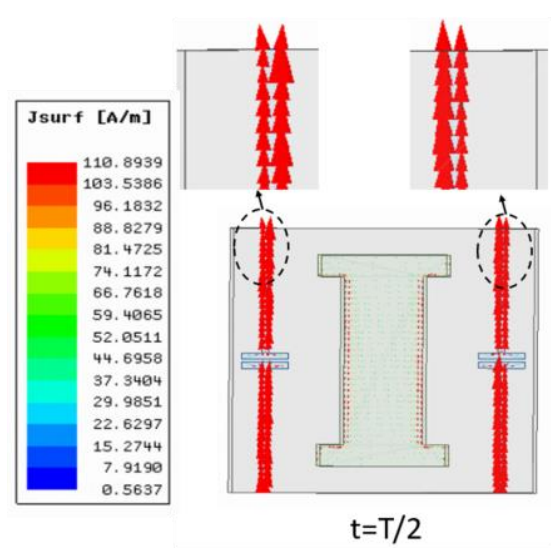

(c)

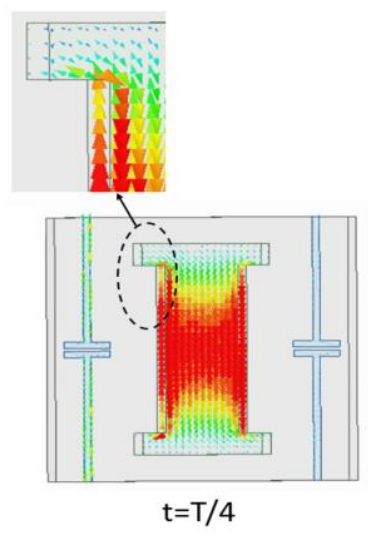

(b)

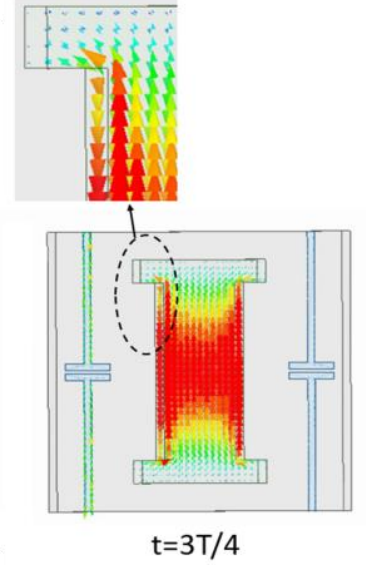

(d)
Fig. 7 Current distributions at specific times in one period T.

\section{CONFORMAL TRANSMITARRAY DESIGN}

To verify the feasibility of the Huygens elements designed above, a small cylindrically conformal transmitarray is constructed with $10 \times 11=110$ elements, and its contour is provided in Fig. 8. The transmitarray aperture is bended along $\mathrm{y}-\mathrm{z}$ plane (H-plane of the gain horn) to make the "I" and " $\mathrm{T}$ " shape patches aligned with the E-field of the feed horn, thereby maximizing the realized gain of the transmitarray. A standard gain horn LB-75-10-C-SF from A-INFO is placed at the focal point with an edge illumination of $-10 \mathrm{~dB}$. The gain at $10 \mathrm{GHz}$ of LB-75-10-C-SF from the data sheet is $10.15 \mathrm{~dB}$. The simulated input reflection coefficient of the antenna is below $-10 \mathrm{~dB}$ from $9.6 \mathrm{GHz}$ to $10.4 \mathrm{GHz}$, as given in Fig. 9 (a), and its realized-gain patterns at $10 \mathrm{GHz}$ along E plane and $\mathrm{H}$ plane are plotted in Fig. 9 (b). The peak gain is $16.7 \mathrm{dBi}$, which corresponds to a $47.3 \%$ antenna efficiency considering the gain calculated by the aperture cross section size $(75.7 \mathrm{~mm}$ $\times 93.5 \mathrm{~mm}$ ). The simulated cross-polarization levels are very small, lower than $-40 \mathrm{~dB}$. For the sake of clarity, they are not given in Fig. 9. 


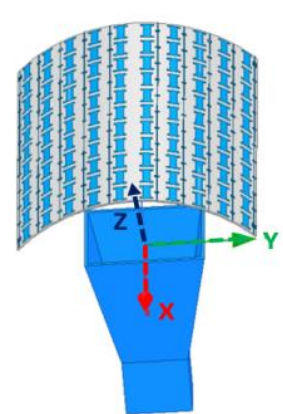

(a)

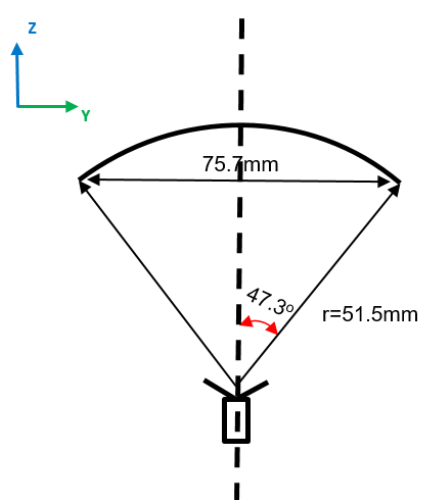

(b)
Fig. 8 Conformal Transmitarray: (a) 3D structure; (b) sketch of front view.

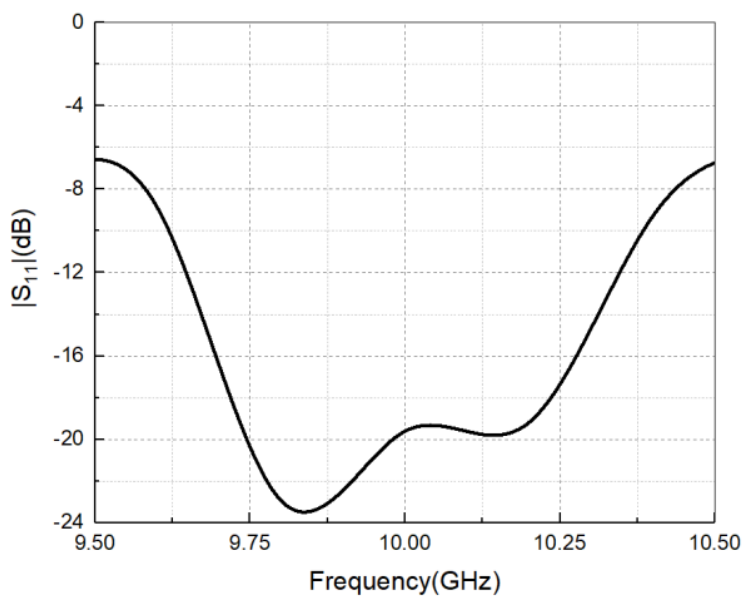

(a)

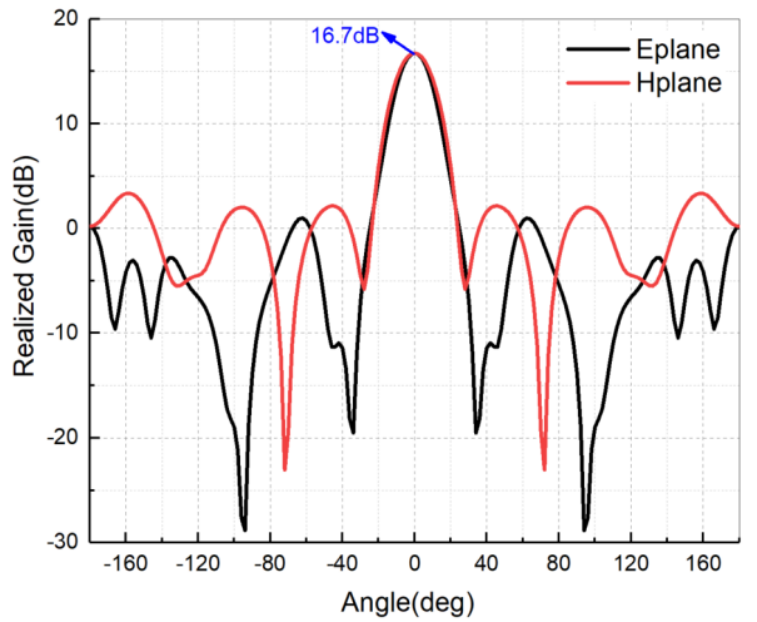

(b)

Fig. 9 Simulated results of conformal transmitarray: (a) $\left|S_{I 1}\right|$ versus frequency; (b) E plane and $\mathrm{H}$ plane patterns at $10 \mathrm{GHz}$.

It is known that the performance of Huygens surface is sensitive to the incidence angle [32]. As indicated in Fig. 10, when element 1 is simulated under different incidence angles, its amplitude and phase of $S_{21}$ change with the angle. In the previous Huygens element simulation, a normal incidence is adopted. For the conformal transmitarray design, however, different incident angles should be considered for each element synthesis. As shown in Fig. 11 (a), along X-z plane, we can divide our model into 11 zones. Considering the structure symmetry, there are 6 zones illuminated with different angles $\theta_{s}$.

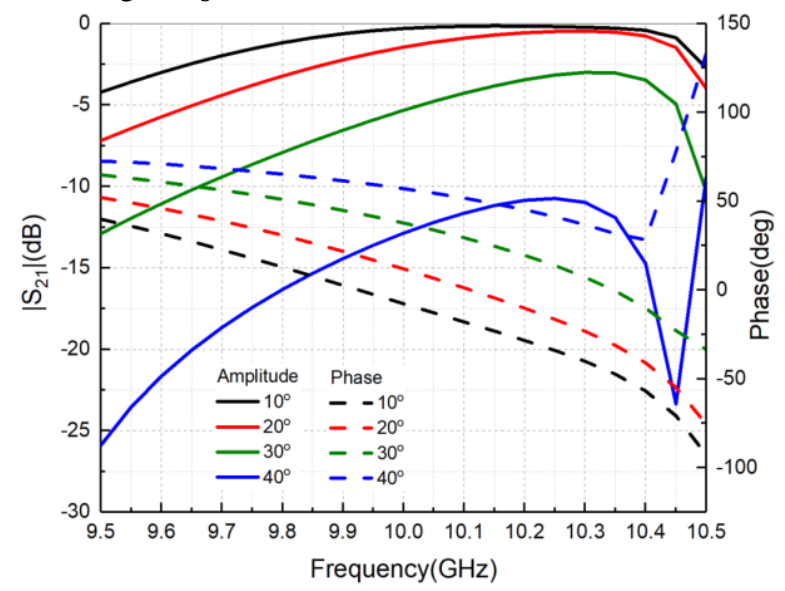

Fig. 10 Simulated $S_{21}$ amplitude and phase of element 1 under different oblique incidence angles.

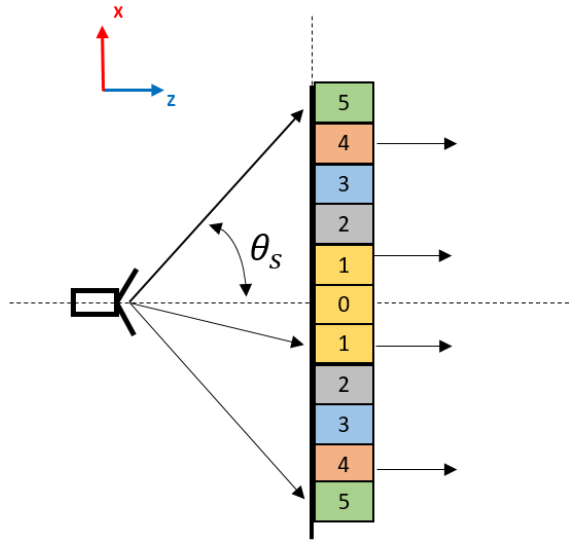

(a)

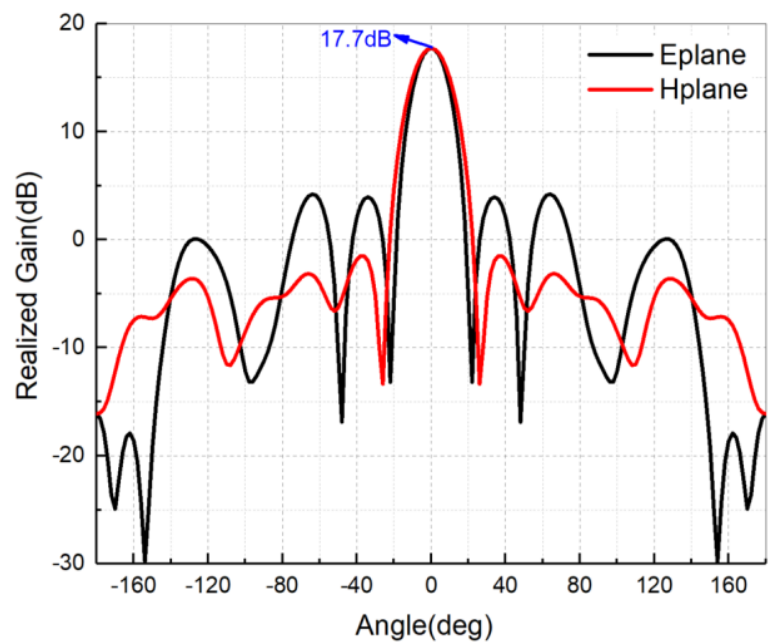

(b)

Fig. 11 Conformal transmitarray design with oblique incidence consideration: (a) Schematic with different zones along X-Z section; (b) Simulated radiation patterns of $\mathrm{E}$ plane and $\mathrm{H}$ plane. 
TABLE IV

PROPERTIES OF ELEMENT 1 UNDER DIFFERENT OBLIQUE INCIDENCE ANGLES

\begin{tabular}{|c|c|c|c|c|c|c|c|}
\hline $\begin{array}{c}\text { District } \\
\text { No. }\end{array}$ & $\begin{array}{c}\text { Oblique } \\
\text { incidence } \\
\text { angle } \theta_{s}\end{array}$ & $\begin{array}{c}\left|\mathrm{S}_{21}\right| \\
/ \mathrm{dB}\end{array}$ & $\angle S_{21}$ & $\begin{array}{c}\mathrm{Wz} \\
/ \mathrm{mm}\end{array}$ & $\begin{array}{c}\mathrm{Wc} \\
/ \mathrm{mm}\end{array}$ & $\begin{array}{c}\mathrm{Lc} \\
/ \mathrm{mm}\end{array}$ & $\begin{array}{c}\mathrm{Ld} \\
/ \mathrm{mm}\end{array}$ \\
\hline 0,1 & $0^{\circ}$ & -0.16 & $-14^{\circ}$ & 3.6 & 1.3 & 0.1 & $/$ \\
\hline 2 & $18^{\circ}$ & -0.2 & $-11^{\circ}$ & 3.6 & 1.4 & 0.1 & $/$ \\
\hline 3 & $26^{\circ}$ & -0.14 & $-13^{\circ}$ & 3.6 & 1.5 & 0.05 & $/$ \\
\hline 4 & $33^{\circ}$ & -0.1 & $-15^{\circ}$ & 3.6 & 1.5 & 0.7 & 0.6 \\
\hline 5 & $39^{\circ}$ & -0.18 & $-12^{\circ}$ & 3.6 & 1.5 & 0.9 & 0.8 \\
\hline
\end{tabular}

For a more accurate design, each Huygens element developed in the last section should be re-designed under specific oblique incidence angles. As the incident angle $\theta_{s}$ for Zone 1 is very small, it is integrated with Zone 0 and the elements are still simulated using normal incidence wave. For elements in Zones 2-5, their dimensions are re-designed for each corresponding angle. Taking element 1 with $\angle \mathrm{S}_{21}=-14^{\circ}$ as an example, the element model is re-simulated after changing the scan angle values in the master-slave boundary settings of HFSS, and the updated dimensions under each situation are listed in Table IV. Compared to the model under normal incidence with dimensions listed in Table II, $W_{c}$ and $L_{c}$ of the element are changed, while $W_{z}$ is unchanged. As observed in Table IV, the larger the incidence angle is, the higher the capacitance from head-to-head ' $T$ stub' is required. In order to increase the capacitance, $L_{c}$ needs to be reduced and/or $W_{c}$ needs to be increased. For some cases, additional interdigital parasitic strips are needed to increase the capacitance (shown as inset of Fig. 2). These design rules are also suitable for other seven elements. The dimensions for the other seven elements are given in the Appendix. Finally, along each zone we employ the elements developed at the corresponding incidence angles. The cylindrical transmitarray with new elements is simulated, and the realized-gain patterns are shown in Fig. 11 (b). Compared with the results shown in Fig. 8, the peak gain at boresight is improved from $16.7 \mathrm{dBi}$ to $17.7 \mathrm{dBi}$ with a significantly reduced back lobe from $0 \mathrm{dBi}$ to $-17 \mathrm{dBi}$, the aperture efficiency is improved to $58 \%$.

\section{EXPERIMENTAL VERIFICATION}

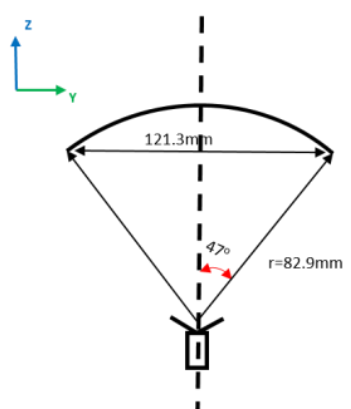

(a)

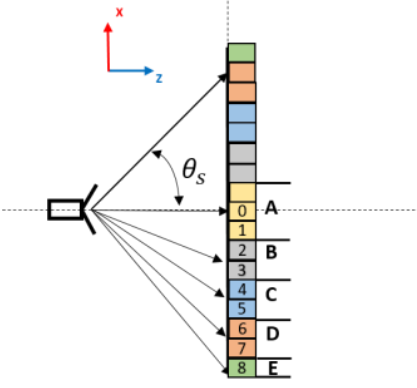

(b)
Fig. 12 Sketch of the cylindrical transmitarray with a larger aperture size: (a) circular section; (b) straight section.
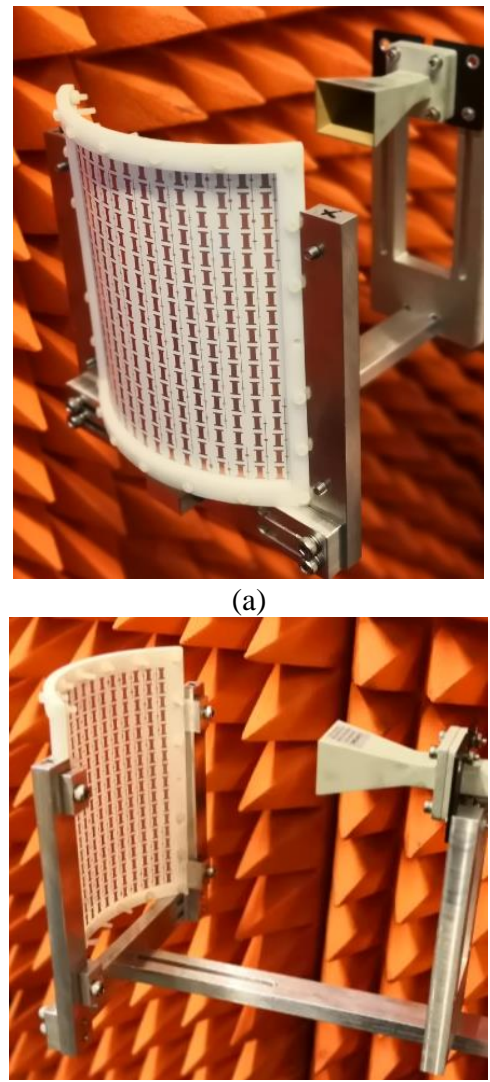

(b)

Fig. 13 Photograph of the conformal transmitarray prototype: (a) Front View; (b) Back View.

Finally, in order to validate the developed ultra-thin Huygens element and its feasibility in conformal transmitarrays, an array with a larger aperture than the one discussed in the last section is designed, fabricated and measured. It includes $16 \times 17=272$ elements, and its dimensions are given in Fig. 12. The cross section size of the transmitting surface is $121.3 \mathrm{~mm} \times 144.5 \mathrm{~mm}$. As discussed in last section, the oblique incidence angles are considered for the array design by dividing the straight section into 5 zones denoted as A, B, C, D, E, as given in Figure. 12 (b). Then, each element listed in Table II is re-simulated under 4 oblique angles, i.e. $14^{\circ}$ (Zone B), $25^{\circ}$ (Zone C), $33^{\circ}$ (Zone D), $39^{\circ}$ (Zone E). The unfolded transmitting surface was fabricated using standard PCB technology on low-cost Wangling F4B substrates (Dielectric Constant 3.55, $\tan \delta=0.0027$ ). Due to its ultra-thin profile which is only $0.5 \mathrm{~mm}\left(\lambda_{0} / 60\right.$ at $\left.10 \mathrm{GHz}\right)$, it can be easily bent onto a 3D printed cylindrical frame. Photograph of the transmitarray prototypes is shown in Fig. 13.

The input reflection coefficients of the transmitarray are measured and compared with the simulated one, as plotted in Fig. 14. It can be seen that they are below $-10 \mathrm{~dB}$ from 9.5$10.5 \mathrm{GHz}$. Far-field radiation patterns are measured using a Microwave Vision Group (MVG) compact range antenna measurement system located at University of Technology Sydney, Ultimo, Australia. 


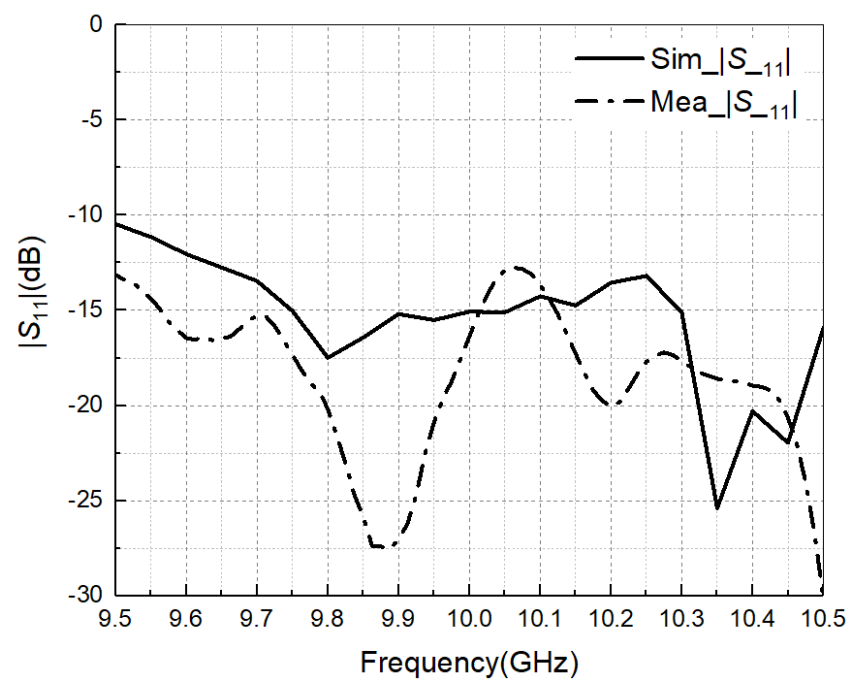

Fig. 14 Simulated and measured results of input reflection coefficients.

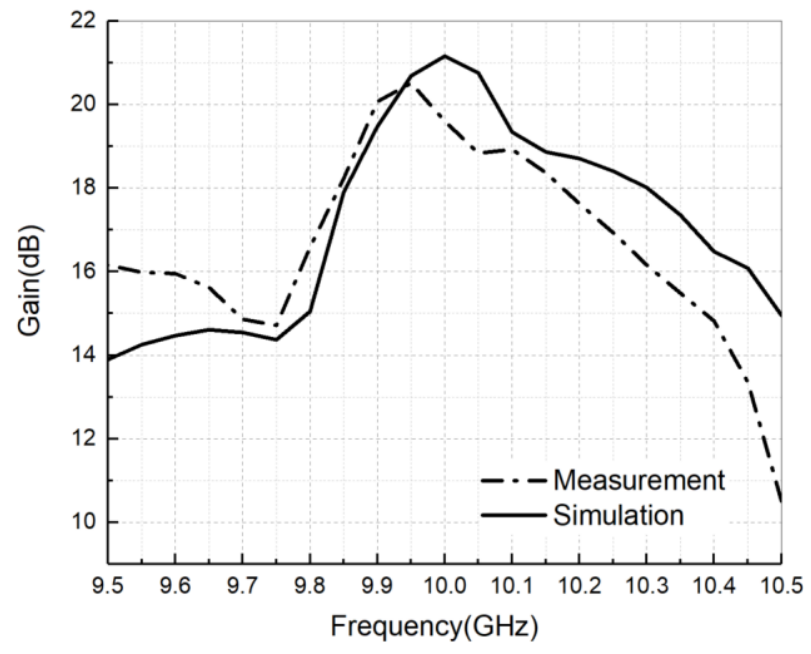

Fig. 15 Simulated and measured gains at boresight versus frequency.

The simulated and measured realized gains versus frequency are also found and plotted in Fig.15. The peak gain appears at $10 \mathrm{GHz}$ in simulation with $21.2 \mathrm{dBi}$, achieving a $54 \%$ antenna efficiency. For the measured results, the maximum gain is at $9.95 \mathrm{GHz}$ with the value of $20.6 \mathrm{dBi}$, corresponding to a $47 \%$ antenna efficiency. The $3-\mathrm{dB}$ gain bandwidth is $3.7 \%(9.83 \mathrm{GHz}-10.2 \mathrm{GHz})$. The simulated and measured $\mathrm{E}$ - and $\mathrm{H}$ - plane radiation patterns at $9.95 \mathrm{GHz}$ are compared in Fig. 16 (a) and (b), respectively. Good agreement can be found except for a slight beam tilt of about $1^{\circ}$. The measured cross-polarization levels for two planes are lower than $-15 \mathrm{~dB}$. The simulated cross-polarization levels are very low, so they are not shown in the figures.

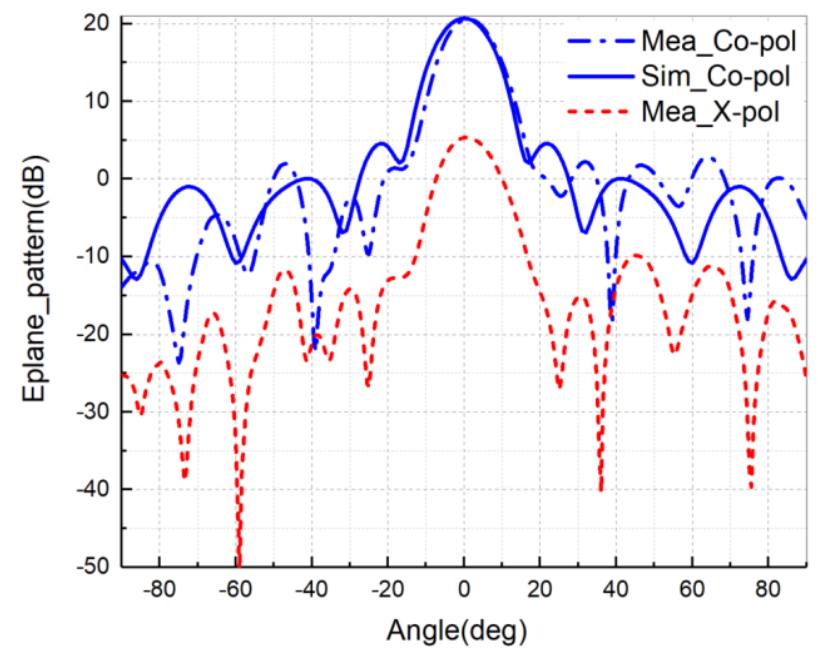

(a)

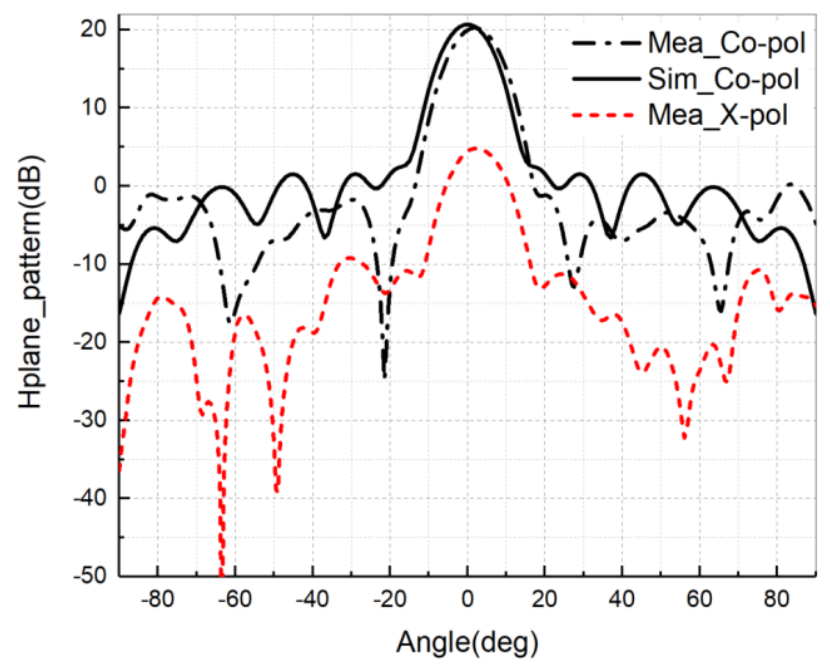

(b)

Fig. 16 Simulated and measured patterns: (a) E plane (b) $\mathrm{H}$ plane.

TABLE V

COMPARISON OF PROPOSED DESIGN WITH REFERENCED TRANSMITARRAYS

\begin{tabular}{|c|c|c|c|c|c|c|}
\hline $\begin{array}{c}\text { Ref. } \\
\text { No. }\end{array}$ & $\begin{array}{c}\text { Dielectric } \\
\text { Constant }\end{array}$ & $\begin{array}{c}\text { Number } \\
\text { of layers }\end{array}$ & $\begin{array}{c}\text { Electrical } \\
\text { thickness }\end{array}$ & Vias & $\begin{array}{c}\text { Array } \\
\text { Contour }\end{array}$ & $\begin{array}{c}\text { Aperture } \\
\text { Efficiency }\end{array}$ \\
\hline 6 & 2.2 & 3 & $\lambda_{0} / 5$ & N. & Planar & $40.7 \%$ \\
\hline 12 & 3.55 & 3 & $\lambda_{0} / 14$ & N. & Planar & $30 \%$ \\
\hline 13 & 4.3 & 2 & $\lambda_{0} / 10$ & N. & Planar & $26 \%$ \\
\hline 22 & 2.55 & 2 & $\lambda_{0} / 10$ & Y. & Planar & $40 \%$ \\
\hline 25 & 2.2 & 3 & $\lambda_{0} / 25$ & N. & Cylindrical & $25.1 \%$ \\
\hline $\begin{array}{c}\text { This } \\
\text { work }\end{array}$ & 3.55 & 2 & $\lambda_{0} / 60$ & N. & Cylindrical & $47 \%$ \\
\hline
\end{tabular}

The slight beam tilt and the discrepancy on the realize gains can be mostly attributed to the fabrication inaccuracies in the $3 \mathrm{D}$ printed cylindrical frame that have effects on the curvature of the transmitting aperture. Furthermore, there would be some alignment errors and the low-cost PCB board may have a varied dielectric constant from the datasheet. 
To the best of the authors' knowledge, this is the first conformal transmitarray with thinnest element and a high aperture efficiency ever reported. The dual-layer structure without any vias is also an important innovation suitable for other transmitarrays where a thin transmitting panel is needed. We compare the results of the developed work with those of other transmitarrays with thin elements, as given in Table V. It can be seen that the proposed one has the thinnest structure while a very high aperture efficiency.

\section{CONCLUSION}

In order to meet the low profile demand on array elements for conformal transmitarray design, Huygens metasurface theory is employed in this work to achieve both ultra-thin array element and a high aperture efficiency. The developed Huygens element consists of two metal layers with an entire thickness of $0.5 \mathrm{~mm}\left(\lambda_{0} / 60\right.$ at $\left.10 \mathrm{GHz}\right)$ and without any via. By tuning magnetic and electric responses properly, eight elements are designed to cover quantized $360^{\circ}$ phase range with a maximal $1.67 \mathrm{~dB}$ loss. Based on those elements, a small conformal transmitarray is constructed, where, oblique incidence on the array aperture is considered to enhance the antenna's performance. Finally, a cylindrically conformal transmitarray with a larger aperture size is simulated and fabricated with a $20.6 \mathrm{dBi}$ measured gain and a $47 \%$ aperture efficiency.

\section{APPENDIX}

PROPERTIES OF ELEMENTS 2-8 UNDER DIFFERENT OBLIQUE INCIDENCE ANGLES

\begin{tabular}{|c|c|c|c|c|c|c|c|}
\hline \multicolumn{8}{|c|}{ Element $2\left(\angle S_{21}=-41^{o}\right)$} \\
\hline $\begin{array}{c}\text { District } \\
\text { No. }\end{array}$ & $\begin{array}{c}\text { Oblique } \\
\text { incidence } \\
\text { angle } \theta_{S}\end{array}$ & $\begin{array}{l}\left|\mathrm{S}_{21}\right| \\
/ \mathrm{dB}\end{array}$ & $\angle S_{21}$ & $\begin{array}{c}\mathrm{Wz} \\
/ \mathrm{mm}\end{array}$ & $\begin{array}{c}\mathrm{Wc} \\
/ \mathrm{mm}\end{array}$ & $\begin{array}{c}\mathrm{Lc} \\
/ \mathrm{mm}\end{array}$ & $\begin{array}{c}\mathrm{Ld} \\
/ \mathrm{mm}\end{array}$ \\
\hline 0,1 & $0^{\circ}$ & -0.42 & $-41^{\circ}$ & 3.8 & 1.6 & 0.1 & 1 \\
\hline 2 & $18^{\circ}$ & -0.3 & $-38^{\circ}$ & 3.8 & 1.4 & 0.05 & 1 \\
\hline 3 & $26^{\circ}$ & -0.18 & $-33^{\circ}$ & 3.8 & 1.75 & 0.05 & 1 \\
\hline 4 & $33^{\circ}$ & -0.17 & $-34^{\circ}$ & 3.8 & 1.5 & 1 & 0.9 \\
\hline 5 & $39^{\circ}$ & -0.12 & $-31^{\circ}$ & 3.8 & 1.5 & 1.6 & 1.5 \\
\hline \multicolumn{8}{|c|}{$\begin{array}{c}\text { Element } \mathbf{3}\left(\angle \boldsymbol{S}_{\mathbf{2 1}}=-\mathbf{1 0 0} \boldsymbol{0}^{\circ}\right) \\
\text { Note: No 'T' stubs are added in this model. }\end{array}$} \\
\hline $\begin{array}{c}\text { District } \\
\text { No. }\end{array}$ & $\begin{array}{l}\text { Oblique } \\
\text { incidence } \\
\text { angle } \theta_{S}\end{array}$ & $\begin{array}{l}\left|S_{21}\right| \\
/ d B\end{array}$ & $\angle S_{21}$ & $\begin{array}{c}\mathrm{Wz} \\
/ \mathrm{mm}\end{array}$ & $\begin{array}{l}\mathrm{Wc} \\
/ \mathrm{mm}\end{array}$ & $\begin{array}{c}\mathrm{Lc} \\
/ \mathrm{mm}\end{array}$ & $\begin{array}{c}\mathrm{Ld} \\
/ \mathrm{mm}\end{array}$ \\
\hline 0,1 & $0^{\circ}$ & -1 & $-100^{\circ}$ & 4.1 & 1 & 1 & 1 \\
\hline 2 & $18^{\circ}$ & -1 & $-99^{\circ}$ & 4.1 & 1 & 1 & 1 \\
\hline 3 & $26^{\circ}$ & -1 & $-97^{\circ}$ & 4.1 & 1 & I & 1 \\
\hline 4 & $33^{\circ}$ & -0.9 & $-92^{\circ}$ & 4.1 & 1 & 1 & 1 \\
\hline 5 & $39^{\circ}$ & -0.7 & $-88^{\circ}$ & 4.1 & 1 & 1 & 1 \\
\hline \multicolumn{8}{|c|}{ Element $4\left(\angle S_{21}=-153^{\circ}\right)$} \\
\hline $\begin{array}{c}\text { District } \\
\text { No. }\end{array}$ & $\begin{array}{c}\text { Oblique } \\
\text { incidence } \\
\text { angle } \theta_{S}\end{array}$ & $\begin{array}{l}\left|\mathrm{S}_{21}\right| \\
/ \mathrm{dB}\end{array}$ & $\angle S_{21}$ & $\begin{array}{c}\mathrm{Wz} \\
/ \mathrm{mm}\end{array}$ & $\begin{array}{l}\mathrm{Wc} \\
/ \mathrm{mm}\end{array}$ & $\begin{array}{c}\mathrm{Lc} \\
/ \mathrm{mm}\end{array}$ & $\begin{array}{c}\mathrm{Ld} \\
/ \mathrm{mm}\end{array}$ \\
\hline 0,1 & $0^{\circ}$ & -1.67 & $-153^{\circ}$ & 4.19 & 1.2 & 0.6 & 1 \\
\hline 2 & $18^{\circ}$ & -1.6 & $-159^{\circ}$ & 4.19 & 1.4 & 0.6 & 1 \\
\hline 3 & $26^{\circ}$ & -1.63 & $-151^{\circ}$ & 4.19 & 1.4 & 0.6 & 1 \\
\hline 4 & $33^{\circ}$ & -1.6 & $-155^{\circ}$ & 4.19 & 1.5 & 0.6 & 1 \\
\hline 5 & $39^{\circ}$ & -1.6 & $-154^{\circ}$ & 4.19 & 1.6 & 0.6 & 1 \\
\hline \multicolumn{8}{|c|}{ Element $5\left(\angle S_{21}=-187^{\circ}\right)$} \\
\hline $\begin{array}{l}\text { District } \\
\text { No. }\end{array}$ & $\begin{array}{c}\text { Oblique } \\
\text { incidence } \\
\text { angle } \theta_{S}\end{array}$ & $\begin{array}{l}\left|\mathrm{S}_{21}\right| \\
/ \mathrm{dB}\end{array}$ & $\angle S_{21}$ & $\begin{array}{c}\mathrm{Wz} \\
/ \mathrm{mm}\end{array}$ & $\begin{array}{l}\mathrm{Wc} \\
/ \mathrm{mm}\end{array}$ & $\begin{array}{c}\mathrm{Lc} \\
/ \mathrm{mm}\end{array}$ & $\begin{array}{c}\mathrm{Ld} \\
/ \mathrm{mm}\end{array}$ \\
\hline
\end{tabular}

\begin{tabular}{|c|c|c|c|c|c|c|c|}
\hline 0,1 & $0^{\circ}$ & -1.66 & $-187^{\circ}$ & 4.2 & 1.2 & 0.37 & 1 \\
\hline 2 & $18^{\circ}$ & -1.73 & $-187^{\circ}$ & 4.2 & 1.3 & 0.37 & 1 \\
\hline 3 & $26^{\circ}$ & -1.8 & $-180^{\circ}$ & 4.2 & 1.4 & 0.37 & 1 \\
\hline 4 & $33^{\circ}$ & -1.7 & $-178^{\circ}$ & 4.2 & 1.5 & 0.37 & 1 \\
\hline 5 & $39^{\circ}$ & -1.73 & $-180^{\circ}$ & 4.2 & 1.5 & 0.3 & 1 \\
\hline \multicolumn{8}{|c|}{ Element $6\left(\angle S_{21}=-241^{o}\right)$} \\
\hline $\begin{array}{l}\text { District } \\
\text { No. }\end{array}$ & $\begin{array}{c}\text { Oblique } \\
\text { incidence } \\
\text { angle } \theta_{s} \\
\end{array}$ & $\begin{array}{l}\left|S_{21}\right| \\
/ \mathrm{dB}\end{array}$ & $\angle S_{21}$ & $\begin{array}{l}\mathrm{Wz} \\
/ \mathrm{mm}\end{array}$ & $\begin{array}{l}\mathrm{Wc} \\
/ \mathrm{mm}\end{array}$ & $\begin{array}{c}\mathrm{Lc} \\
/ \mathrm{mm}\end{array}$ & $\begin{array}{c}\mathrm{Ld} \\
/ \mathrm{mm}\end{array}$ \\
\hline 0,1 & $0^{\circ}$ & -1.36 & $-241^{\circ}$ & 4.25 & 1.5 & 0.4 & 1 \\
\hline 22 & $18^{\circ}$ & -1.38 & $-239^{\circ}$ & 4.25 & 1.6 & 0.4 & 1 \\
\hline 3 & $26^{\circ}$ & -1.36 & $-244^{\circ}$ & 4.25 & 1.6 & 0.3 & I \\
\hline 4 & $33^{\circ}$ & -1.39 & $-242^{\circ}$ & 4.25 & 1.5 & 0.2 & 1 \\
\hline 5 & $39^{\circ}$ & -1.43 & $-234^{\circ}$ & 4.25 & 1.4 & 0.15 & 1 \\
\hline \multicolumn{8}{|c|}{ Element $7\left(\angle S_{21}=-284^{o}\right)$} \\
\hline $\begin{array}{l}\text { District } \\
\text { No. }\end{array}$ & $\begin{array}{c}\text { Oblique } \\
\text { incidence } \\
\text { angle } \theta_{s}\end{array}$ & $\begin{array}{l}\left|\mathrm{S}_{21}\right| \\
/ \mathrm{dB}\end{array}$ & $\angle S_{21}$ & $\begin{array}{c}\mathrm{Wz} \\
/ \mathrm{mm}\end{array}$ & $\begin{array}{l}\mathrm{Wc} \\
/ \mathrm{mm}\end{array}$ & $\begin{array}{c}\mathrm{Lc} \\
/ \mathrm{mm}\end{array}$ & $\begin{array}{c}\mathrm{Ld} \\
\mathrm{mm}\end{array}$ \\
\hline 0,1 & $0^{\circ}$ & -0.86 & $-284^{\circ}$ & 4.3 & 1.62 & 0.4 & 1 \\
\hline 2 & $18^{\circ}$ & -0.84 & $-286^{\circ}$ & 4.3 & 1.5 & 0.3 & 1 \\
\hline 3 & $26^{\circ}$ & -0.81 & $-287^{\circ}$ & 4.3 & 1.45 & 0.2 & 1 \\
\hline 4 & $33^{\circ}$ & $\begin{array}{l}-0.8 \\
\end{array}$ & $-288^{\circ}$ & 4.3 & 1.7 & 0.2 & 1 \\
\hline 5 & $39^{\circ}$ & -0.82 & $-288^{\circ}$ & 4.3 & 1.5 & 0.1 & 1 \\
\hline \multicolumn{8}{|c|}{ Element $8\left(\angle S_{21}=-330^{\circ}\right)$} \\
\hline $\begin{array}{l}\text { District } \\
\text { No. }\end{array}$ & $\begin{array}{c}\text { Oblique } \\
\text { incidence } \\
\text { angle } \theta_{s}\end{array}$ & $\begin{array}{l}\left|S_{21}\right| \\
/ \mathrm{dB}\end{array}$ & $\angle S_{21}$ & $\begin{array}{c}\mathrm{Wz} \\
/ \mathrm{mm}\end{array}$ & $\begin{array}{c}\mathrm{Wc} \\
/ \mathrm{mm}\end{array}$ & $\begin{array}{c}\mathrm{Lc} \\
/ \mathrm{mm}\end{array}$ & $\begin{array}{c}\mathrm{Ld} \\
/ \mathrm{mm}\end{array}$ \\
\hline 0,1 & $0^{\circ}$ & -0.5 & $-330^{\circ}$ & 4.4 & 1.62 & 0.35 & 1 \\
\hline 2 & $18^{\circ}$ & -0.45 & $-328^{\circ}$ & 4.4 & 1.6 & 0.3 & 1 \\
\hline 3 & $26^{\circ}$ & -0.46 & $-333^{\circ}$ & 4.4 & 1.6 & 0.2 & 1 \\
\hline 4 & $33^{\circ}$ & -0.42 & -330 & 4.4 & 1.45 & 0.1 & 1 \\
\hline 5 & $39^{\circ}$ & $\begin{array}{l}-0.4 \\
\end{array}$ & $-332^{\circ}$ & 4.4 & 1.7 & 0.1 & 1 \\
\hline
\end{tabular}

\section{REFERENCES}

[1] Q. Luo, S. Gao, W. Liu, C. Gu, "Low-cost smart antennas," John Wiley \& sons, March 2019.

[2] S. Gaber, S. H. Zainud-Deen and H. A. E. Malhat, "Analysis and design of reflectarrays/transmitarrays antennas," LAP LAMBERT Academic Publ, 2014.

[3] L. Dussopt, "Transmitarray antennas", in A. Boriskin and R. Sauleau (eds), Aperture Antennas for millimeter and sub-millimeter wave applicatons, Springer 2018.

[4] A. H. Abdelrahman, P. Nayeri, A. Z. Elsherbeni, and F. Yang, "Bandwidth improvement methods of transmitarray antennas,"IEEE Trans. Antennas Propag., vol. 63, no. 7, pp. 2946-2954, Jul. 2015.

[5] A. H. Abdelrahman, A. Z. Elsherbeni, and F. Yang, "High Gain and Broadband Transmitarray Antenna Using Triple-Layer Spiral Dipole Elements," IEEE Antennas Wireless Propag. Lett., vol. 13, pp. 12881291, Jul. 2014.

[6] P.-Y. Feng, S.-W. Qu, and S. Yang, "Octave Bandwidth Transmitarrays With a Flat Gain," IEEE Trans. Antennas Propag., vol. 66, no. 10, pp. 5231-5238, Oct. 2018.

[7] B. Rahmati, H. R. Hassani, "High-efficient wideband slot transmitarray antenna," IEEE Trans. Antennas Propag., vol 63, no. 11, pp.5149-5155, Nov. 2015.

[8] K. T. Pham, R. Sauleau, E. Fourn, F. Diaby, A. Clemente and L. Dussopt, "Dual-band transmitarrays with dual-linear polarization at Ka band,"IEEE Trans. Antennas Propag., vol. 65, no. 12, pp. 7009-7018, Dec. 2017.

[9] A. Aziz , F. Yang, S. Xu, and M. Li, "An Efficient Dual-Band Orthogonally Polarized Transmitarray Design Using Three-Dipole Elements", IEEE Antennas Wireless Propag. Lett., vol. 17, no. 2, pp. 319-322, Feb. 2018.

[10] C. Tian, Y.-C. Jiao, and G. Zhao, "Circularly polarized transmitarray antenna using low-profile dual-linearly polarized elements," IEEE Antennas Wireless Propag. Lett., vol. 16, pp. 465-468, 2017. 
[11] M. Al-Joumayly and N. Behdad, "Wideband planar microwave lenses using sub-wavelength spatial phase shifters," IEEE Trans. Antennas Propag., vol. 59, no. 12, pp. 4542-4552, Dec. 2011.

[12] Q. Luo, Steven Gao, M. Sobhy, X.Yang, Z.-Q. Cheng, Y.-L. Geng, J. T. S. Sumantyo,"A Hybrid Design Method for Thin Panel Transmitarray Antennas," IEEE Trans. Antennas Propag., Early access, 2019.

[13] H. Li, G. Wang, J. Liang, X. Gao, H. Hou, and X. Jia, "Single-layer focusing gradient metasurface for ultrathin planar lens antenna application," IEEE Trans. Antennas Propag., vol. 65,no. 3, pp. $1452-$ 1457, Mar. 2017.

[14] Y. Ge, C. Lin, Y. Liu, "Broadband Folded Transmitarray Antenna Based on an Ultrathin Transmission Polarizer," IEEE Trans. Antennas Propag., vol. 66, no. 11, pp. 5974-5981, Aug. 2018.

[15] L. Palma, A. Clemente, L. Dussopt, R. Sauleau, P. Potier, and P. Pouliguen, "Circularly-Polarized Reconfigurable Transmitarray in KaBand With Beam Scanning and Polarization Switching Capabilities," IEEE Trans. Antennas Propag., vol. 65, no. 2, pp. 529-540, Feb. 2017.

[16] C. Huang, W. Pan, X. Luo, "Low-Loss Circularly Polarized Transmitarray for Beam Steering Application," IEEE Trans. Antennas Propag., vol. 64, no. 16, pp. 4471-4476, Oct. 2016.

[17] J. Y. Lau and S. V. Hum, "A wideband reconfigurable transmitarray element," IEEE Trans. Antennas Propag., vol. 60, no. 3, pp. 1303$1311,2012$.

[18] J. G. Nicholls, and S. V. Hum, "Full-Space Electronic Beam-steering Transmitarray With Integrated Leaky-Wave Feed," IEEE Trans. Antennas Propag., vol. 64, no. 8, pp. 3410-3422, 2016.

[19] T. Su, X.Yi, B. Wu, "X/Ku Dual-Band Single-Layer Reflectarray Antenna," IEEE Antennas Wireless Propag. Lett., vol. 18, pp. 338342, Jan. 2019.

[20] Z.-W. Miao, Z.-C. Hao, Q. Yuan, "Design and Implementation of a GBand Silicon-Based Single-Layer Reflectarray Antenna," IEEE Antennas Wireless Propag. Lett., vol. 16, pp. 2191-2194, May 2017.

[21] L. Guo, H. Yu, W. Che, W. Yang, "A Broadband Reflectarray Antenna Using Single-Layer Rectangular Patches Embedded With Inverted LShaped Slots," IEEE Trans. Antennas Propag., vol. 67, no.5, pp. 3132-3139, Feb. 2019.

[22] W. An, S. Xu, F. Yang, and M. Li, "A Double-layer transmitarray antenna using malta crosses with vias," IEEE Trans. Antennas Propag., vol. 64, no. 3, pp. 1120-1125, Mar. 2016.

[23] M. Beccaria, P. Pirinoli, F. Yang, "Preliminary results on Conformal Transmitarray Antennas, 'In 2018 IEEE International Symposium on Antennas and Propagation \& USNC/URSI National Radio Science Meeting, pp. 265-266, IEEE, 2018

[24] T. A. Hill, J. R. Kelly, M. Khalily, T. W. C. Brown, "Conformal Transmitarray for Scan Loss Mitigation with Thinned Reconfiguration," In 13th European Conference on Antennas and Propagation (EuCAP), pp. 1-5, IEEE. 2019

[25] P.-Y. Qin, L.-Z. Song, Y. J. Guo, “ Beam Steering Conformal Transmitarray Employing Ultra-Thin Triple-Layer Slot Elements," IEEE Trans. Antennas Propag., vol. 67, no. 8, pp. 5390-5398, Aug. 2019.

[26] S. B. Glybovski, S. A. Tretyakov, P. A. Belov, Y. S. Kivshar, C. R. Simovski, "Metasurfaces: From microwaves to visible," Physics Reporots, vol.634, pp.1-72, May 2016.

[27] J. P. S. Wong, M. Selvanayagam,, G. V. Eleftheriades, "Design of unit cells and demonstration of methods for synthesizing Huygens metasurfaces," Photonics and Nanostructures-Fundamentals and Applications, 12 , no. 4, pp. 360-375. 2014.

[28] C. Pfeiffer and A. Grbic, "Millimeter-wave transmitarrays for wavefront and polarization control," IEEE Trans. Microw. Theory Techn., vol.61, no.12, pp. 4407-4417, 2013.

[29] C. Pfeiffer and A. Grbic, "Metamaterial Huygens' surfaces: Tailoring wave fronts with reflectionless sheets," Phys. Rev. Lett., 110, no. 19, 197401, May 2013.

[30] K. Chen, Y. Feng, F. Monticone et al., "A reconfigurable active Huygens' metalens,” Adv. Mater., 29, no. 17, 1606422 , May 2017.
[31] B. O. Zhu, et al., " Dynamic control of electromagnetic wave propagation with the equivalent principle inspired tunable metasurface," Sci. Rep., 4, 4971, May 2014.

[32] A. Epstein and G. V. Eleftheriades, "Huygens' metasurfaces via the equivalence principle: design and applications," J. Opt. Soc. Am. B, 33, no. 2, pp. A31-A50, Feb. 2016.

[33] M. Selvanayagam and G. V. Eleftheriades, "Circuit modelling of Huygens surfaces," IEEE Antennas Wireless Propag. Lett., 12, pp. 1642-1645, Dec. 2013.

[34] W. Lin, R. W. Ziolkowski, J. Huang, "Electrically Small, Low-Profile, Highly Efficient, Huygens Dipole Rectennas for Wirelessly Powering Internet-of-Things Devices," IEEE Trans. Antennas Propag., vol. 67, no. 6, pp. 3670-3679, Mar. 2019. 